roo in each of these attacks. The year $189 \mathrm{I}$ is referred to as the worst period, but at the date mentioned the Registrar-General says "one death was primarily attributed to influenza." In lieu of $189 \mathrm{I}$ the year 1892 should have been given, when for the week ending January 23 the deaths in London were 506. The quiescence of the disease lasting three-and-twenty years is scarcely tenable, as shown by the above facts.

The total number of deaths from influenza for the past summer epidemic was 929 (not 1600 ), based on the reasoning followed in all epidemics since 1890 . In the attack now in progress the total deaths $(37 \mathrm{I})$ in London for the week ending October 19 were more than in any epidemic since 1895, when the deaths in the week ending March 19 were 473 .

Since 1890 no influenza epidemic has occurred in London in September, only one (the present year) in August, two in October, two in July, three in June, and four in November. Of the total twenty-eight epidemics twenty-four have occurred in March and twenty-one in February.

Although the weather secms to have little bearing on the disease, the temperature generally has been abnormally high and the air humid at the outbreak of several of the epidemics, whilst when the air becomes cold and dry the incidence of the disease is commonly reduced.

$6_{5}$ Holmewood Gardens, London, S.W.

\section{Supplies of Amœba proteus for Laboratories.}

ONE of the ways in which the war has interfered with zoological teaching in this country is by cutting off supplies of various of the animal types which are examined by the student in the laboratory. Amongst these, as has already been indicated by letters to NATURE, is Amoba - the animal with the study of which many zoological courses commence.

It is easy enough to obtain Amœbæ of a kind, but what the teacher requires is a supply of the large Amcoba which commonly goes under the name $A$, proteus. Of this, again, it is easy enough to obtain a few specimens, but the teacher-at least, if he has a class of nearly four hundred students, as is the case in this University-must be able to obtain a thousand or more specimens on a particular date.

With the object of grappling with our local difficulties in this matter, Dr. Monica Taylor, S.N.D., has been so good as to make a special study of the distribution of $A$. proteus in the neighbourhood of Glasgow, and of its culture in the laboratory. Pending the publication of her paper on the subject, I think it may be useful to other teachers of zoology if I summarise in a few words her chief results.

During the months June to December A. proteus seems to be of general occurrence in moorland lakes and ponds, while it disappears from December to May-no doubt becoming encysted, as described by Miss L. Carter (Proc. Roy. Phys. Soc. Edin., vol. xix., I9 $\left.1_{5}\right)$. The main conditioning factors of its occurrence appear to be abundant food supply and a rich supply of oxygen. An apparently ideal spot is one where richly oxygenated water from the overflow of a pond passes over mud rich in organic débris.

The supplies of Amœba obtained in such a locality are placed in aquaria in which the water is richly aerated either by water-weed or by a special apparatus, and as a source of food supply grains of wheat are mixed with the mud, as suggested by Hrman. In this way Dr. Taylor has succeeded, as she says, in obtaining "millions" of Amœebæ in laboratory cultures.

University of Glasgow, October 22.

\section{ALCOHOL IN INDUSTRY.}

JOT the least remarkable result of the war on 1 this country will be its effect on the development of chemical industry, and especially in the application of organic chemistry to the chemical arts. This, of course, has primarily resulted from the cutting off of the large supplies of manufactured organic products-mainly synthetic dyes and drugs, photographic chemicals, and numerous other substances comprehended under the term "fine chemicals" -which prior to I9I4 mainly came to us from Germany. Thrown thus upon our own resources, we were compelled, in the interests of national health and welfare, to attempt the manufacture of certain of the more important of these products. Great difficulties were experienced at the outset, owing to our lack of experience and the absence of skilled assistance. The supply of chemists with any real training in the application of organic chemistry to industry was very far short of the sudden demand. We were overtaken by a Nemesis invoked by our own inactivity and lack of foresight. It is only within recent years that the teaching of organic chemistry has received any considerable amount of attention in our universities and technical colleges. For the most part it has been regarded as a purely academic subject, to be studied in the interests of pure science, and with no thought to its technical application as a branch of manufacturing chemistry. Except to the few who sought to fit themselves for a career in science, mainly as teachers, there was little or no inducement to pursue its study, as there were very few opportunities in this country to turn a knowledge of it to practical account.

The situation at the outbreak of war was further aggravated by the action of the Army authorities in drafting such trained men as were available into the combatant ranks. But, notwithstanding thes disadvantageous circumstances, an astonish amount of progress has been made. As regarcs medicaments our manufacturers have risen to the demands made upon them. In spite of many setbacks due to inexperience and ignorance, and lack of adequate plant, we have it on the test mony of the highest authorities that the Services are now adequately supplied with every needful drug. In this respect our men, and the country generally, are infinitely better off than our enemies. It is notorious that Germany, in spite of all her boasted power of organisation, has failed lamentably in meeting the necessities of her Medical Service, and an untcld amount of suffering, permanent injury, and a greatly increased mortality have thereby résulted.

As regards synthetic dyes, if the progress has not been relatively so striking or so adequate as in the case of drugs, it has at least been very considerable. We are very far from being alongside Germany yet, either in the amount or the range of our output, but we are in a fair way of being able to meet our more urgent demands. It is impossible in five years to make up the leeway of fifty, especially of fifty years of strenuous and 
almost feverish activity. With the blessed prospect of peace now in sight, it is hopeless to expect that we shall wholly catch up our rivals. Indeed, it will require skilful handling, both on the part of the Government and of our manufacturers, to safeguard the position we have already won.

But whatever the future may have in store, it is quite certain that applied organic chemistry in this country has received a great impetus, and that it is destined to become an increasingly important factor in our chemical industry. In certain subordinate branches, indeed, the ground gained has already been consolidated. German competition in the case of some organic products is no longer in question. Not only have we succeeded in manufacturing these substances; we are also turning them out of better quality than heretofore and rapidly securing a world-wide market for them.

In view of the prospect before us the problem of the supply of alcohol for industrial purposes acquires a fresh importance. It has been in the past a somewhat thorny question, made needlessly acute by misunderstanding and misrepresentation. It has been complicated by fiscal considerations, and by the attitude of a Treasury which was more concerned in safeguarding and securing revenue from this source than in appreciating the demands of industry. The Treasury, although ultimately responsible, may plead that it is not wholly to blame, since in this matter it is dependent upon its official advisers, who, being for the most part persons attached to revenue departments, could not be assumed to be altogether unbiased. Still, in spite of official inertia and conservatism, the revenue authorities have, of late years, become increasingly sympathetic with the needs of manufacturers, and concessions and relaxations which twenty years ago would not have been contemplated are now readily obtainable. A stumblingblock is the necessity for denaturing. Woodnaphtha costs more than ordinary spirit, hence methylated spirit is more expensive than duty-free common alcohol. In some cases the presence of methyl alcohol, or the substances associated with it in the crude commercial article, are positively detrimental. The Excise authorities have appreciated these objections by allowing manufacturers to denature the alcohol by the use of some substance which is ancillary to the manufacture of the article for which the alcohol is needed, and at the same time renders the spirit unpotable.

It can scarcely be doubted that industry will need much larger quantities of alcohol than have hitherto been available, and increased attention will need to be paid to possible sources of supply. It is not only in industrial chemistry and in many other arts that alcohol is required. It is beginning to receive consideration in this country as fuel, and particularly in internal-combustion engines. Up to the present time the use of alcohol as motor fuel with us has not been a commercial possibility; it could not be produced at a price that would compete with petrol at pre-war figures. CircumNo. 2557 , VOL. IO2] stances have, however, changed, and it is unlikely that any form of motor-spirit will sink, at all events for some time to come, to the prices of 1914. Nor is it probable that the raw materials which have hitherto served for the manufacture of alcohol in this country will for years reach their former low values. These substances for the most part have been cereals, or some form of starchproducing, and therefore potential sugar-producing, material. In addition, considerable quantities of spirit have been made from molasses and other saccharine substances capable of fermentation. Potatoes with us are too valuable as a food to be employed, as in Germany, for the manufacture of alcohol.

But there are other modes of obtaining alcohol than from substances which can be used for food, and it is this circumstance that has induced $\mathrm{Mr}$. Long to appoint the Committee to which we made reference in Nature for October 17 . Large quantities of spirit are now obtained from the sulphite liquors in the manufacture of wood-pulp, and factories for the manufacture of alcohol by this process have been established in Sweden, North Germany, America, and elsewhere. To such an extent has the manufacture developed in Sweden that the Government is contemplating a monopoly of the wholesale trade in technical spirit - a measure which has aroused considerable opposition in industrial circles. We learn that a company with a minimum capital of $1,000,000$ kronor has been founded in Stockholm to manufacture and sell motors and automobiles run on sulphite spirit.

The process of treating seaweed, to which Sir Edward Thorpe directed attention in a recent letter to the Times, is a method of saccharifying cellulose material very similar in principle to that employed in the wood-pulp industry. Factories to exploit seaweed in Sweden have been or are being erected at Varberg and in Skane, probably on lines similar to those worked in Glasgow. Considering the enormous quantities of valuable seaweeds to be met with on our coasts, especially among the Western Isles of Scotland and on the west coast of Ireland, it is to be regretted that no effective steps are taken to turn them to practical account. Although formerly of considerable commercial value, the only use that is now made of them is to a limited extent as manure on land adjacent to the shores on which they are gathered. Only an infinitesimal amount of that readily available is so used, and it seems a pity that material so intrinsically valuable should not be dealt with more efficiently.

\section{EPIDEMIC CATARRHS AND INFLUENZA.}

THE present epidemic of influenza, and the rise in the rate of mortality consequent upon it, are receiving much attention in the public Press, and many irresponsible statements are being made concerning the disease. Among these is the hint that the "so-called influenza" is plague in a thin disguise. These erroneous views may at once be discounted. There is no doubt, as Prof. Hewlett 